\title{
Comparative Analysis of Hepatitis B Virus Infections in Blood Donors Born Before and After the I Mplementation of Universal HBV Vaccination in Southern China
}

\author{
Xianlin Ye \\ Shenzhen Blood Center \\ Tong Li \\ Shenzhen Blood Center \\ Yi Li \\ Shenzhen Blood Center \\ Jinfeng Zeng \\ Shenzhen Blood Center
}

Ran Li

Shenzhen Blood Center

Xiaoxuan Xu

Shenzhen Blood Center

\section{Xiaoyu Guan}

Chinese Academy of Medical Sciences and Peking Union Medical College $\otimes$ School of Public Health, Anhui Medical University

Ling Li ( $\square$ lling@ibt.pumc.edu.cn )

Chinese Academy of Medical Sciences and Peking Union Medical College

\section{Research}

Keywords: Hepatitis B virus, The universal HBV vaccination program, Blood donors, Mutations

Posted Date: November 6th, 2020

DOl: https://doi.org/10.21203/rs.3.rs-101501/v1

License: (1) This work is licensed under a Creative Commons Attribution 4.0 International License.

Read Full License 
Comparative analysis of hepatitis B virus infections in blood donors born before and after the implementation of universal HBV vaccination in Southern China

Xianlin $\mathrm{Ye}^{1}$,Tong $\mathrm{Li}^{1}$,Yi $\mathrm{Li}^{1}$,Jinfeng Zeng ${ }^{1}$, Ran $\mathrm{Li}^{1}$, Xiaoxuan $\mathrm{Xu}^{1}$, Xiaoyu Guan ${ }^{2,4}$, Ling $\mathrm{Li}^{2,3 *}$

${ }^{1}$ Shenzhen Blood Center, Shenzhen, Guangdong, China, 518035

${ }^{2}$ Chinese Academy of Medical Sciences and Peking Union Medical College, 610052,

Chengdu, Sichuan Province, P.R. China

${ }^{3}$ Key laboratory of transfusion adverse reactions, CAMS, 610052, Chengdu, Sichuan Province, P.R. China

${ }^{4}$ School of Public Health, Anhui Medical University, 230032, Hefei, Anhui Province, P.R. China

*Corresponding author: Ling Li

E-mail addresses: 1ling@ibt.pumc.edu.cn

Address: 26 Huacai Rd, Longtan Industry Zone.

Chenghua District, Chengdu, Sichuan P. R. of China 


\section{ABSTRACT}

Background: Neonatal hepatitis $B$ vaccination program at birth has been implemented nationwide since 1992 in China, which may impact HBV safety in blood donations actively. The true prevalence of $\mathrm{HBV}$, HBsAg, and $\mathrm{OBI}$ between vaccinated blood donors and non-vaccinated blood donors should be explored.

Study design and methods: The samples of blood donors were collected and detected for serologic markers of HBV in the Shenzhen Blood Center between Feb 2016 and Jun 2016. The discrepant results were tested with commercial electrochemiluminescence immunoassay (ELCI), alternative MPX ID NAT, nested PCR, sequencing, and a quantitative real-time polymerase chain reaction (PCR) assay. HBsAg and anti-HBs were quantified. The serological and molecular characteristics of HBV infected blood donors were analyzed, and the effects on blood safety for donors born before and after the implementation of universal HBV vaccination were compared.

Results: Total of 242 reactive by NAT and/or HBsAg ELISA samples from 26318 candidate donors, $192(0.73 \%$, [95\%CI, 0.63-0.84]) HBV+, 131 (0.49\%, [95\%CI, 0.43-0.59]) $\quad \mathrm{HBsAg}+, \quad 58 \quad(0.22 \%, \quad[95 \% \mathrm{CI}, 0.17-0.28])$ OBI were confirmed respectively. The HBV+ rate in vaccinated donors is lower than in non-vaccinated donors $(\mathrm{P}<0.05)$. The HBsAg titers of vaccinated infected blood donors are much higher than non vaccinated infected blood donors. The OBI yield rates in the vaccinated blood donors were $0.11 \%(7 / 6422)$, and significantly lower than $0.26 \%$ $(51 / 19898)$ in the non vaccinated blood donors $(\mathrm{P}<0.05) .102 / 124(82.3 \%)$ samples are genotype B, 22/124 (17.7\%) are genotype C total. There is no significant difference in the distribution of genotype in the non vaccinated blood donors $(\mathrm{B} / \mathrm{C}, 86 / 17)$ and the vaccinated blood donors $(\mathrm{B} / \mathrm{C}, 23 / 6)(\mathrm{P}>0.05)$. High frequency of vaccine escape mutation M133L (32.4\%) and E164G in S region of genotype B strains and substitution L175S (40.9\%) related to vaccine escape in S region of genotype $\mathrm{C}$ strains identified.

Conclusion: The universal HBV vaccination program markedly reduces the risk of HBV infection in blood donors, and provides a significant guarantee for the safety of 
blood transfusion. Several important mutations detected related vaccine escape and notable mutations needed further investigated.

Keywords: Hepatitis B virus; The universal HBV vaccination program; Blood donors; Mutations

\section{Background}

Hepatitis B Virus (HBV) is one of the most frequent and detrimental causes of liver infection in humans [1]. One-third of the world's population is estimated to have been infected by HBV. Each year approximately 620,000 individuals die from HBV-related illnesses, including acute fulminant infection, cirrhosis, and hepatocellular carcinoma [2,3]. also, roughly about 4.5 million new HBV infections occur worldwide each year, of which a quarter progresses to liver disease [4]. In China, chronic hepatitis B has ranked first among the 27 infectious diseases reported by the Chinese government for more than ten years, and about $60 \%$ of the Chinese population has a history of HBV infection, and $7.18 \%$ are chronic carriers of hepatitis B surface antigen (HBsAg) [5]. HBV has become the leading threat to blood safety.

Hepatitis B virus surface antigen (HBsAg) Screening implemented 40 years ago progressively decreased the risk of transfusion transmission. The sensitivity of HBsAg screening assays considerably improved over time. Still, it remains unable to detect the pre-seroconversion window period or samples with a very low viral load after decades of chronicity or clinical recovery [6]. With the development, the availability of HBV nucleic acid testing (NAT) in blood for transfusion enabled the testing of donated blood and the identification of variable prevalence of HBV DNA carriers in asymptomatic donors negative for HBsAg. However, deficient viral DNA levels in blood donors with occult HBV infection (OBI) are intermittently or not detectable even by highly sensitive individual donation (ID) NAT [7]. In contrast, anti-HBc screening can eliminate nearly all HBV present in chronically infected or recovered individuals, which carries detectable HBV DNA, and resulting in a decrease in the risk of post-transfusion HBV infection [8].

To control hepatitis $\mathrm{B}$, the Chinese government has implemented infant 
vaccination with hepatitis B vaccine as the highest priority in 1992 and resulted in a significant carrier reduction rate in children from $10 \%$ to $<1 \%$ over two decades [5]. These vaccinated populations enrolled in blood donors since 2010. HBV vaccines are gradually becoming the majority of blood donors in China and definitely could impact blood safety positively. Moreover, to reduce the risk of blood transmitted viruses further, China has begun to implement NAT as an option in routine blood screening in 2010. From 2015, China has adopted this technique adequately nationwide. With the combination of sensitive HBsAg screening and vaccination programs, this measurement would control the HBV blood safety in a high endemic area. Shenzhen is a modern immigrant city in Southern China. Blood donors are relatively young and proportionally well educated. With government budget support, Shenzhen Blood Center (SZBC) began to implement MP NAT as an option in routine blood screening from 2003 . In 2009, we decided to use ID NAT (Ultrio assay) as mandatory testing for identifying more low-level viral carriers. The window period (WP) and occult infections (OBI) of HBV were identified by several NAT assays from blood donations in a previous study [9-11]. To ensure maximal blood safety, from Feb 2015, SZBC adopted more sensitive ID NAT (Ultrio Plus) with enhanced analytical sensitivity for HBV DNA detection. This decision was taking into consideration that it would detect lower levels of virus and, therefore, would further reduce the transmission risk by blood from donors in the WP or with OBI.

However, the previous report suggested that HBV vaccine made of genotype A2 recombinant protein might not be fully efficient when used in other genotype prevalent areas. Low anti-HBs level induced by vaccination protects against hepatitis B diseases and chronic infection, but favor occult infection [6]. To test this hypothesis, a large group of Chinese blood donors, including presumed vaccinated or non vaccinated recruited by SZBC, were tested and identified for HBV serologic and molecular markers. This was conducted to investigate the recent true epidemiology of HBV infection and the effectiveness of the vaccination program for the prevention of the data of HBsAg+ and/or HBV DNA+ blood donors after individual-donation. This study was intended to examine the effectiveness of the vaccination program and 
explore the potential threat of vaccination failures to the blood supply.

\section{Material and methods}

\section{Subjects and samples}

A total of 26318 eligible voluntary and non-remunerated blood donors were enrolled in this study from Jan 2016 to Jun 2016, in order to investigate whether the expected impact of the national neonatal vaccination program implemented in 1992 in blood donors was confirmed. The presumed vaccinated and non-vaccinated blood donor populations were separated into two groups, according to being born before or after Jan 1, 1992. Blood donors as born after Jan 1, 1992, were designated as vaccinated donors. Blood donors born before Jan 1, 1992, were selected as non-vaccinated donors. Thus 6421 (24.4\%) donors for vaccinated groups, and 19897 $(75.6 \%)$ donors for the non-vaccinated groups were available in this study. All donors in this study were given the pre-donation questionnaire, and donors who tested reactive on the rapid assay were deferred. Rapid pre-donation testing for HBsAg (colloidal gold strip method, Abon Diagnostics, Hangzhou, China), alanine aminotransferase (ALT) (Roche Refletron, Roche Diagnostics Gmbh, Mannheim, Germany) and hemoglobin (Copper sulfate gravity method) were performed at the collection sites. Qualified donors were further tested with dual ELISA assays (two primary immunoassays at the same time, not sequential) for HBsAg (DiaSorin S.P.A.-UK Branch and Wantai Diagnostics, Beijing, China). Blood samples with HBsAg reactivity in at least one ELISA assay were subjected to re-testing in duplicate. Samples reactive in any assay on re-testing were determined to be HBsAg ELISA+. First-time blood donors were defined as donors who gave blood for the first time, while repeat-donors were defined as donors who donated blood more than once at the SZBC.

All donors were tested individually by NAT for HBV, HCV, and HIV-1 genomes with the multiplex Procleix Ultrio plus assay (Grifols Diagnostic Solutions, Inc. and Hologic). Individual reactive samples were further tested with a discriminatory Procleix Ultrio plus test to identify the virus responsible for NAT 
reactivity (HBV, $\mathrm{HCV}$, or $\mathrm{HIV}-1)$ as the manufacturer recommends. If necessary, MPX2.0 ID NAT was used as an alternative NAT assay for further identification. Serum and aliquots of the index-retrieved frozen plasma unit for HBsAg ELISA+ and/ or NAT initial reactive were collected for additional determination.

\section{Supplemental serological testing, HBsAg quantitation, and HBsAg+ confirmation}

HBsAg (LOD: $0.05 \mathrm{IU} / \mathrm{mL}$ ), anti-HBs (LOD: $2 \mathrm{IU} / \mathrm{L}$ ), hepatitis B e antigen (HBeAg), anti-HBe, and hepatitis B core antibodies (anti-HBc) of all HBsAg ELIA+ and/ or NAT initial reactive samples were tested and quantified by commercially available ECLI (Roche, USA). Any sample testing repeats reactive/ positive by supplemental HBsAg assays with HBV DNA+ was considered HBsAg confirmed positive (HBsAg+).

\section{HBV DNA confirmation}

HBV DNA was extracted from 200ul-2500 $\mu$ l of plasmas with HBsAg ELIA+ and/ or NAT initial reactive by HighPure Viral Nucleic Acid Large Volume Kits (Roche Diagnostics Gmbh, Mannheim, Germany), and was further determined by a combination of qPCR and nested PCRs amplifying the basic core promoter/ pre-core $(\mathrm{BCP} / \mathrm{PC})$ and $\mathrm{S}$ regions as previously described $[10,11]$. Samples reactive by any two assays of five NATs were confirmed DNA positive. The experiments were performed in a standard PCR laboratory to avoid any contamination, Negative controls and positive control were always included in every nested PCR test. Donations that tested HBsAg+ and HBV DNA+ with anti-HBc were designed as chronic hepatitis infections (CHB), donations that tested HBsAg- and HBV DNA+ with anti-HBc and/ or anti-HBs were OBIs, Donations that tested HBsAg- and HBV DNA+ without any seromarkers were WPs.

\section{HBV DNA sequencing, genotyping and comparison}


To confirm HBV genotypes, the amplified PCR products obtained from the $\mathrm{BCP} / \mathrm{PC}$ (295 bp) and the S regions (495 bp) were purified by the AxyPrep DNA gel extraction kit (AXYGEN) and sent to Shanghai Invitrogen Co., Ltd. (Guangzhou, China) for sequencing. The nucleotide sequences and the references from GenBank were aligned and manually adjusted using the BioEdit program. HBV genotype determination was performed by phylogenetic analysis using the MEGA7.0 program. The neighbor-joining method with 1,000 bootstrap replications was applied. The amino acid sequences from 124 genotype B (subtype B1-B7) and 95 genotype C (subtype C1-C7) isolated from HBsAg+ blood donors from Taiwan, Hongkong, Thailand, and Malaysia were selected as reference sequences (kindly provided by Dr. Daniel Candotti) [12]. The amino acid sequences of the HBV positive samples were matched with the reference sequences, and each amino acid that occurred at every position was calculated statistically.

\section{Statistical analyses}

Ninety-five percent confidence intervals $(95 \% \mathrm{CI})$ for the observed yield rate were derived using the binomial exact proportion method. Categorical variables were compared using 'Fisher's exact test and, for continuous variables, the non-parametric Mann-Whitney test. A $P$-value of $<0.05$ was used as the cut-off level for significance.

\section{Results}

\section{Demographic Characteristics and Screening results of blood donors samples}

Six thousand four hundred twenty-one vaccinated and 19897 non-vaccinated blood donors were enrolled in this study, the demographic characteristics of vaccinated and non-vaccinated donors were shown in table 1. After and screened by dual ELISAs and NAT,154 (0.59\%) samples were HBsAg ELISA positive including $113(0.43 \%)$ for HBsAg ELISA+/NAT initial reactive (IR), 88 samples were NAT IR/HBsAg ELISA-, among which 34/88 were positive for discriminatory HBV test (dHBV), and 54 multiplex NAT reactive, but negative for discriminatory HBV/HCV/HIV test (non-repeat reactive, NRR)(Fig.1).

Confirmatory results of HBsAg ELISA+ samples and HBV DNA NAT IR 
samples

Of $154 \mathrm{HBsAg}$ ELISA positive samples, 129 (83.8\%) cases were confirmed HBsAg+ by ECLI and DNA+ by 4 alternative NATs, including 113/113 (100\%) HBsAg ELISA+/NAT IR samples and 18/41 (43.9\%) for HBsAg ELISA+/NATsamples. In 34 HBsAg ELISA-/dHBV+ and 54 HBsAg ELISA-/NAT NRR samples tested by nested PCRs, qPCR and MPX ID NAT, 31/34 dHBV+ samples were confirmed HBV DNA+, and 31/54 (57.4\%) NAT NRR samples were confirmed DNA+ too. In total, $192(0.74 \%)$ confirmed HBV+ (Table 2).

\section{Statistical result of demographic characteristics and testing results}

Successful HBV S gene sequencing followed by genotyping and serotyping was performed for 124 of the 192 samples, which composed the vaccinated group and non-vaccinated group. The results showed statistically significant differences $(\mathrm{P}<$ 0.05 ) in sex, number of first time and repeated time donors, occupation distribution, education distribution, the rate of $\mathrm{HBV}+$, mean $\mathrm{HBsAg}$ titers, Anti-HBc+/Anti-HBs+ pattern, and OBI yield rate, the distribution of anti-HBs titers between the two groups (Table 1, Table2); however, no significant differences in the distribution of HBV genotype, and the median of anti-HBs titers between the two groups were found $(\mathrm{P}>$ $0.05)$.

Prevalence of HBV, HBsAg, and OBI between blood donors born before and after the universal infant vaccination program

192/26318 (0.73\%, [95\%CI, 0.61-0.82]) HBV+, 131/26318 (0.50\%, [95\%CI, 0.41-0.58]) HBsAg+, 58/26318 (0.22\%, [95\%CI, 0.16-0.28]) OBI were detected and verified in the eligible blood donors population respectively. Of $192 \mathrm{HBV}+$ blood donors, 36 were vaccinated donors, and 154 were non-vaccinated donors, The rate of $\mathrm{HBV}+$ in the vaccinated donors is lower than in the non-vaccinated donors $(\mathrm{P}<0.05)$. Of $131 \mathrm{HBsAg}$ confirmed positive donors, 28 (0.44\%) were vaccinated donors, and $103(0.52 \%)$ were non-vaccinated donors. Of 58 cases OBIs, $7(0.11 \%)$ were 
vaccinated donors, and $50(0.26 \%)$ were non-vaccinated donors. There is a significant difference between the two groups $(\mathrm{P}<0.05)$.

\section{S gene sequencing and Phylogenetic analysis}

Two hundred forty-two samples were amplified by nested PCR, 124 cases were got s sequences. In the non-vaccinated group, 95 were got s sequences, $79(83.1 \%)$ were genotype B, 16 (16.9\%) were genotype C. And in the vaccinated group, 29 samples were got s sequences, 23 (79.3\%) were genotype B, 6 (19.7\%) were genotype $\mathrm{C}$ respectively. There is no difference between the two groups for genotype distribution $(\mathrm{P}=0.790>0.05)$.

\section{Mutation analysis within or out of MHR in identified HBV+ donations}

$\mathrm{S}$ sequences including the major hydrophilic region (MHR) from 124 samples (non-vaccinated group: 79 genotype $\mathrm{B}$ and 16 genotype $\mathrm{C}$ strains; vaccinated group: 23 genotype $\mathrm{B}$ and 6 genotype $\mathrm{C}$ strains) were analyzed. Compared with reference amino acids, the occurrence of the donations' amino acid substitutions at each position observed with significant difference $(P<0.05)$ were determined as notable mutations [9] (Table 3). For the amino acid sequence encoded by the $\mathrm{S}$ gene from 65 CHBs genotype B samples in non-vaccinated group, N40S/F (40\%), I68T/M (6.2\%), $\mathrm{Q} 101 \mathrm{R} / \mathrm{H} / \mathrm{K}(6.2 \%), \mathrm{M} 133 \mathrm{~L} / \mathrm{T} / \mathrm{S}(27.7 \%)$ and $\mathrm{F} 134 \mathrm{I} / \mathrm{l} / \mathrm{S}(7.8 \%)$ were calculated as notable mutations, and 224 amino-acid substitutions were presented in this group. However, in vaccinated group (CHB), G44D/E (38.1\%), M133L (52.4\%) and E164G $(14.3 \%)$ were notable mutations, the frequency of $\mathrm{M} 133 \mathrm{~L}(47.6 \%)$ mutation were higher than in non-vaccinated group $(\mathrm{CHB}, 16.9 \%, \mathrm{P}<0.05)$. In non-vaccinated OBI group for genotype B, only G44D/E (42.9\%) and M133L (64.3\%) were observed as notable mutations. However, in vaccinated OBI group, all were found K24R, G44D and M133L mutations. Meanwhile, in genotype C donations, Q30K, S34L, N40S, A45T, T47V, P49H, F55S, I68T, P79H, L175S, V177A were notable mutations in non-vaccinated CHB group. T118K, L175S notable mutations were found in vaccinated CHB group. While 11 OBIs (non-vaccinated group), Q30K, N40S, A45T, T47V/K, P49H/L, S55F, R59H, T113P/S/N, T118K/R, S143T/L, R160K/N, L175S and V177A were determined as notable mutations. G145R, G145A, G145E were observed in 1 genotype $\mathrm{C}$ vaccinated $\mathrm{CHB}$ donation, and 1 non-vaccinated $\mathrm{CHB}$ 
donation respectively.

\section{Discussion}

China is endemic for hepatitis $\mathrm{B}$, and the residual risk of transfusion transmission is significantly higher for HBV than for HIV-1 and HCV. HBV NAT has been preliminarily introduced in many major blood centers in China since 2003, and the yield ranged between $1: 1000$ to $1: 10,000$ of which approximately $20 \%$ were pre-seroconversion window period and $80 \%$ occult $\mathrm{HBV}$ infection $(\mathrm{OBI})$, the latter including young donors having been vaccinated to HBV [22]. Over the past two decades, systematic vaccin ation at birth or early childhood in several countries with moderate or high HBV endemicity, including China, resulted in a decrease of HBV incidence. However, vaccination may also favor the development of escape mutants and neutralizing anti-HBs antibodies level decrease over time in vaccinated people who may become susceptible to HBV infection; especially to infection with genotypes different from the one used in the vaccine (HBV genotype A2) [7]. In this study, confirmatory testing algorithms and supplemental testings are used to exclude false-positive results and identified the low-virus-load donations as many investigations [22]. Confirmed positivity was defined based on multiple assay reactivity or sequence generation. Each strain identified was intrinsic to samples and not the result of collection or laboratory contamination to get data as accurate as possible. These measurements would get the real information of HBV infection in blood donors in China with high endemic HBV infection utmostly and could give a better comparison between vaccinated blood donors and non-vaccinated blood donors for the prevalence of $\mathrm{HBV}, \mathrm{HBsAg}$, and OBI. In this study, 242 reactive by NAT and/or HBsAg ELISA samples from 26318 candidate blood donors were investigated, 23/154 (14.9\%), and 27/88 (30.7\%) potential false positive in both serology and NAT were identified respectively. In total, of 192 confirmed HBV infected blood donors, $61(31.3 \%)$ cases were HBsAg-/DNA+, and 131 (60.1\%) were HBsAg+/DNA+ due to adoption of large volume DNA extraction assay. Of 54 NRR samples, 30 donations were clarified $\mathrm{HBsAg}$-/DNA+, a higher NAT yield rate was confirmed compared with 
the multi-regional study [23] and Hongkong study [24].

For blood donation screening, HBsAg is expressed transiently in acute HBV infection and therefore is not sufficiently sensitive as the only HBV marker. The confirmed HBsAg positive rate is $0.50 \%$, which coincides with the report [25]. Compared to the prevalence of typical normal infection among donors in China, those of other countries were much lower: $0.12 \%$ in France [26], $0.23 \%$ in UAE [27], $0.004 \%$ in Britain, even the rates of most countries in Latin American are less than $0.5 \%$ [28]. The severe epidemic of HBV infection among the Chinese population might account for the high prevalence of typical HBV infection among Chinese blood donors. The latest nationwide investigation performed in 2006[5] indicated that the majority among the whole population is $7.18 \%$, although researchers considered this prevalence should be underestimated due to methodological deficiency.

The true interdiction HBV DNA positive rate by Ultrio Plus ID-NAT screening in combination with HBsAg was $0.73 \%$, higher than true $\mathrm{HBsAg}$ positive rate $(0.50 \%$, $\mathrm{P}=0.001$ ), and the true $\mathrm{OBI}$ yield was $1: 453$, nearly had two-fold increase compared with a previous study in Shenzhen [10] due to application of ID NAT. For The Ultrio Plus assay has used a target enhancer reagent, which helps to disrupt viral particles and exposes more single-stranded DNA for the capture probe. This assay modification increased the proportion of OBI yield at least more twofold than the Ultrio assay [24]. Moreover, in the NAT NRR donations, $31.5 \%$ were got sequences, and $38 \%$ were qPCR positive due to shorter length of the primer, overall, 55\% were identified HBV DNA positive in which $100 \%$ were low-virus-load OBI, gained another half of OBI cases. In our study with those reported in other countries, the rate differences varied considerably depending on HBV epidemiology, the proportion of repeat or lapsed donors, NAT technology, and pooling strategy employed; for example, 1:624 in Xiamen China [29], 1:3471 in Hongkong [24], 1:894 in Taiwan [30], 1:4232 in Thailand [31] and 1:770,000 in Germany [32]. The prevalence of OBI among Chinese volunteer blood donors, is also much higher than those of adjacent countries.

Universal $\mathrm{HB}$ vaccination is the best, cost-effective and preventive strategy for HBV control [33]. Since hepatitis B vaccination became mandatory for all newborns 
within $24 \mathrm{~h}$ of birth nationwide in 1992, the HBsAg positive rate in children decreased significantly, from $10 \%$ to $1-2 \%$ [34]. Moreover, data have shown that the prevalence of HBV has consistently declined in recent years [35]. However, the HBV vaccine cannot eliminate emerging HBV infection. The potential causes may originate from the following options: (1) Low level or undetectable anti-HBs induced by vaccination. Those vaccinees with a low level of anti-HBs are susceptible to infection associated with breakthrough or favor occult HBV infections. In China, 5-10\% of the population shows little or more response after HBV vaccination. Even after newborn immunoprophylaxis, vertical transmission still accounts for $5 \%$ of cases of HBV infection in China [36]. Additionally, over $50 \%$ of vaccinated children no longer carry detectable anti-HBs when reaching 11-17 years [37]. In our previous study of 1494 vaccinated blood donors aged 18-21 years in Shenzhen, Southern China, we found approximately $29 \%$ of donors with no detectable HBV markers and $40 \%$ of them carrying anti-HBs levels $<100 \mathrm{IU} / \mathrm{L}$ [38]. (2) HBV vaccine made of genotype A2 recombinant protein might not be fully efficient when used in other genotypes prevalent areas such as genotype B and C commonplace in China. (3) A prevalence of anti-HBc increasing with age consistent with an increasing cumulative HBV exposure suggests that those with poor low-level immune responses were insufficiently protected when in contact with high HBV DNA load mainly through sexual activity. (4) S mutant breakthrough infections may occur in vaccinated people as the mutant strains may infect vaccinated individuals because anti-HBs antibodies induced by the current vaccine may not recognize changes in HBsAg caused by $\mathrm{S}$ gene mutations [39]. During the five months of study, HBV prevalence in vaccinated donors aged 18-24y was lower than in non-vaccinated donors aged 25-60 $(\mathrm{P}<0.05)$. OBI yield rates were also confirmed lower than in non-vaccinated donors $(\mathrm{P}<0.05)$. This difference might be related to the increasing cumulative HBV exposure with the ages, and vaccine-related protection would be the definite cause. The OBIs detected in this report also carry anti-HBs suggesting that OBIs occur primarily in individuals who have recovered from the infection but are unable to develop an effective immune control [40]. Furthermore, among OBI samples, the percentage of those carrying 
anti-HBs in vaccinated OBI blood donors is lower than the non vaccinated. OBI blood donors $(\mathrm{P}<0.05)$, suggest that lower level or less of anti-HBs were insufficiently protected and are susceptible to infection associated with breakthrough or occult HBV infections, even when vaccinated at birth. Interestingly, in HBsAg positive vaccinated blood donors, the titers are much higher than non vaccinated blood donors $(\mathrm{P}<0.005)$, because the infected vaccinated blood donors are no response or warning off vaccinee, HBsAg is secreted more than in usual after infection.

HBV with HBsAg escape mutants are rare but potentially highly infectious and pathogenic, particularly in immune-compromised recipients [41]. The prevalence of the well-known neutralization escape mutation G145R in the HBV envelope protein was as high as $22 \%$ in American blood donors [42]. However, in our study, the G145R mutation was not found in genotype B; only three cases harbored G145A/E/R individually were found in genotype C donations. Furthermore, compared to G145R mutation, several mutations within and out of MHR were detected at too high a prevalence such as M134L and L175S. Surprisingly, the isolates from the CHBs non-vaccinated genotype $\mathrm{B}$ group also showed high variability in their $\mathrm{S}$ gene sequences in comparison with CHBs vaccinated genotype B group. However, the frequency of M133L (52.4\% vs. 16.9\%) and E164G (14.3 vs. 3.1\%) associated with escape from vaccine-induced immunity was observed higher significantly in CHBs vaccinated group than in the CHBs non-vaccinated group $(\mathrm{P}<0.05)$. This is because antibodies induced by the current vaccine may not recognize changes in the surface antigen as a result of mutation. In the genotype $\mathrm{C}$ non-vaccinated group, lots of mutations out of MHR such as Q34K, N40S, T47V, P49H, S55F, L175S, V177A were detected. These mutations are associated with major histocompatibility complex (MHC) class I-restricted cytotoxic CD8+ lymphocytes (CTLs) epitopes, and it has been experimentally proved that adaptive immune response mediated by CTLs is necessary for controlling HBV infection. This may be because mutations in CTL epitopes can evade cellular immunity and contribute to persistency, and are potentially responsible for vaccine breakthrough infection and HBsAg undetectability 
[39]. Interestingly, two membrane-embedded C-terminus mutations L175S, V177A were observed at high frequency in genotype $\mathrm{C}$ donors in the present study and proved tightly to correlate with OBI, and powerfully to affect HBsAg detection [26].

\section{Conclusion}

The prevalence of $\mathrm{HBV}+$ and $\mathrm{OBI}$ in vaccinated donors is lower than in non-vaccinated donors $(\mathrm{P}<0.05)$, suggested that The universal HBV vaccination program markedly reduces the risk of $\mathrm{HBV}$ infection in blood donors. Furthermore, there is a high frequency of mutations in the MHR and out of MHR of the HBV S gene, which may cause vaccine escape, diagnosis failure, and failure in HBIg therapy problem and highlights the need for more studies into the prevalence of mutants.

\section{List of abbreviations}

$\mathrm{HBV}=$ Hepatitis $\mathrm{B}$ virus; $\mathrm{OBI}=$ occult hepatitis $\mathrm{B}$ infection; $\mathrm{CHB}=$ chronic hepatitis B; NAT=nucleic acid testing; ELISA(s)=enzyme-linked immuno-absorbent assay(s); ECLI= electrochemiluminescence immunoassay; ID = individual donation; $\mathrm{LOD}=$ limit of detection; $\mathrm{S} / \mathrm{CO}=$ sample to cutoff; $\mathrm{TMA}=$ transcription-mediated amplification; $\mathrm{IR}=$ initial reactive; $\mathrm{NRR}=$ non repeat reactive; $\mathrm{BCP} / \mathrm{PC}=$ basic core promoter/pre-core; $\mathrm{MHR}=$ major hydrophilic region; $\mathrm{MHC}=$ major histocompatibility complex; HBig=hepatitis B immunoglobulin; CTL=cytotoxic CD8+ lymphocytes.

\section{Declarations}

\section{Ethical approval and consent to participate}

This study was approved by the ethics committee of the Shenzhen Blood Center. The written and informed consent form was obtained from each donor before donation. 


\section{Consent for publication}

Not applicable.

\section{Availability of data and materials}

Not applicable.

\section{Competing interest}

The authors declare that they have no competing interests.

\section{Funding}

This work was support by Shenzhen Natural Science Fund (JCYJ20190806112201646) and Shenzhen Key Medical Discipline Constrstruction Fund (SZXK070), by the CAMS Innovation Fund for Medical Sciences (CIFMS) (Grant Nos. 2016-I2M-3-024).

\section{Authors' contributions}

$\mathrm{XY}$ designed the experiments and wrote and reviewed the manuscript. LL reviewed, revised, and edited the manuscript. All other author participated in the study design, performed the experiments, and collected and analyzed the data. All authors read and approved the final manuscript.

\section{Acknowledgements}

The authors thank Dr. Daniel Candotti for giving guidance for the analysis.

\section{Reference}

[1] Gerlich WH, Bremer C, Saniewski M, Schuttler CG, et al. Occult hepatitis B virus infection: detection and significance. Dig Dis 2010;28:116-25.

[2] WHO. Hepatitis B vaccines: WHO position paper - recommendations. Vaccine 2010; 28: 589-90.

[3] Goldstein ST, Zhou F, Hadler SC, et al. A mathematical model to estimate global hepatitis B disease burden and vaccination impact. Int.J.Epidemiol. 2005,34: $1329-39$.

[4] Alessandro R. Zanetti A, Pierre VD, Daniel S. The global impact of vaccination 
against hepatitis B: A historical overview. Vaccine 2008; 26: 6266-73.

[5] Liang X, Bi S, Yang W, Wang L, Cui G, Cui F, et al. Epidemiological serosurvey of hepatitis $B$ in China-declining HBV prevalence due to hepatitis B vaccination. Vaccine 2009;27:6550-7.

[6] Allain, JP. Occult hepatitis B virus infection: implications in transfusion. Vox Sang 2004;86:83-91.

[7] Candotti D, Boizeau L, Laperche S.Occult hepatitis B infection, and transfusion-transmission risk. Transfus Clin Biol 2017; 24:189-195.

[8] Kleinman SH, Kuhns MC, Todd DS, Glynn SA, McNamara A, DiMarco A, Busch MP. Frequency of HBV DNA detection in US blood donors testing positive for the presence of anti-HBc: implications for transfusion transmission and donor screening. Transfusion 2003; 43: 696-704

[9] Ye X, Li T, Shao W, et al. Nearly half of Ultrio plus NAT non discriminated reactive blood donors were identified as occult HBV infection in South China. BMC infet. 2019. 19(1): 577-87.

[10] Ye X, Yang B, Zhu W, et al. Six-year pilot study on nucleic acid testing for blood donations in China. Trans Aphe Sci 2013;49:318-22

[11] Zheng X, Ye X, Zhang L, et al. Characterization of occult hepatitis B virus infection from blood donors in China. J Clin Microbiol 2011;49:1730-7.

[12]Candotti D, Lin CK, Belkhiri D, Sakuldamrongpanich T, Biswas S, Lin S, Teo D, Ayob Y, Allain JP. Occult hepatitis B infection in blood donors from South East Asia: molecular characterization and potential mechanisms of occurrence. Gut 2012;61: 1744-53.

[13] Hou J, Wang Z, Cheng J, Lin Y, Lau GK, Sun J, Zhou F, Waters J, Karayiannis P, Luo K. Prevalence of naturally occurring surface gene variants of hepatitis B virus in nonimmunized surface antigen-negative Chinese carriers. Hepat 2001;34:1027-1034.

[14] Gish RG, Gutierrez JA, Navarro-Cazarez N, Giang K, Adler D, Tran B, Locarnini S, Hammond R, Bowden S. A simple and inexpensive point-of-care test for 
hepatitis B surface antigen detection: serological and molecular evaluation. J Viral Hepat 2014; $21: 905-08$.

[15] Echevarria JM, Avellon A. Hepatitis B virus genetic diversity. J Med ViroI 2006;78(1): 36-42.

[16] Pourkarim MR, SharifiZ, Soleimani A, Van Ranst, M, et al. Evolutionary analysis of HBV "S" antigen genetic diversity in Iranian blood donors: a nationwide study. J Med Virol.2014;86(1):144-55.

[17] Larralde O, Dow B, Jarvis L, Davidson F, Petrik J. Hepatitis B escape mutants in Scottish blood donors. Med. Microbiol. Immunol. 2013; 202. 207-214.

[18] Lin YM, Jow GM, Mu SC, Chen BF. Naturally Occurring Hepatitis B Virus B-Cell and T-Cell Epitope Mutants in Hepatitis B Vaccinated Children. Sci. Wrld. J.2013;1:571-75.

[19] Svicher V, Cento V, Bernassola M, Neumann-Fraune M, Van Hemert F, Chen M, Salpini R, Liu C, ongo R, Visca M, Romano S, Micheli V, Bertoli A, Gori C, Ceccherini-Silberstein F, Sarrecchia C, Andreoni M, Angelico M, Ursitti A, Spanò A, Zhang JM, Verheyen J, Cappiello G, Perno CF. Novel HBsAg markers tightly correlate with occult HBV infection and strongly affect HBsAg detection. Antiviral Res 2012; 93: 86-93.

[20] Wang J, Qiu J, Zhu Y, Zhou H, Yu L, Ding Y, Zhang L, Guo Z, Dong C: Molecular evolution of hepatitis B vaccine escape variants in China, during 2000-2016. Vaccine 2017; 35(43):5808-5813.

[21] Kalinina T, Riu A, Fischer L, Will H, Sterneck M. A dominant hepatitis B virus population defective in virus secretion because of several S-gene mutations from a patient with fulminant hepatitis. Hepatology 2001;34:385-94.

[22] Allain JP, Candotti D. Diagnostic algorithm for HBV safe transfusion.Blood Transfus 2009;7:174-82.

[23]Lelie N, Bruhn R, Busch M, Vermeulen M, Tsoi WC, Kleinman S, et al.Detection of different categories of hepatitis B virus (HBV) infection in a multi-regional study comparing the clinical sensitivity of hepatitis B surfaceantigen and HBV-DNA testing. Transfusion 2017;57:24-35. 
[24] Tsoi WC, Lelie N, Lin CK. Enhanced detection of hepatitis B virus in Hong Kong blood donors after introduction of more sensitive transcription-mediated amplification assay.Transfusion 2013;53:2477-88

[25]Huang C, Yuan Q, Chen P, et al. Influence of mutations in hepatitis B virus surface protein on viral antigenicity and phenotype in occult HBV strains from blood donors.J hepat 2012;57:720-9

[26] Pillonel J, David D, Pinget R, Laperche S.Prevalence of HBV, HCV, HIV, and HTLV in autologous blood donors in France between 1993 and 2000 (Article in French). Transfus Clin Biol .2002;9: 289-96.

[27] Al Shaer L, AbdulRahman M, John TJ, AlHashimi A. Trends in prevalence, incidence, and residual risk of major transfusion-transmissible viral infections in United Arab Emirates blood donors: impact of individual-donation nucleic acid testing, 2004 through 2009. Transfusion $2012 ; 52: 2300-2309$.

[28] Schmunis GA, Zicker F, Cruz JR, Cuchi P. Safety of blood supply for infectious diseases in Latin American countries, 1994-1997. Am J Trop Med Hyg 2001; 65: 924-930.

[29] Yuan Q, Ou SH, Chen CR, Ge SX, Pei B, Chen QR, et al. Molecular characteristics of occult hepatitis B virus from blood donors in southeast China. J Clin Microbiol 2010;48:357-362.

[30] Li L, Chen PJ, Chen MH, Chak KF, Lin KS, Tsai SJ. A pilot study for screening blood donors in Taiwan by nucleic acid amplification technology: detecting occult hepatitis $\mathrm{B}$ virus infections and closing the serologic window period for hepatitis $\mathrm{C}$ virus. Transfusion 2008;48:1198-206.

[31] Louisirirotchanakul S, Oota S, Khuponsarb K, Chalermchan W, Phikulsod S, Chongkolwatana V, Sakuldamrongpanish T, Kitpoka P, Chielsilp P, Tanprasert S, Tirawatnapong T, Wasi C; Working Group for NAT Study in Thai Blood Donations. Occult hepatitis B virus infection in Thai blood donors. Transfusion 2011;51:1532-40. [32] Hourfar MK, Jork C, Schottstedt V, et al. German Red Cross NAT Study Group. Experience of German Red Cross blood donor services with nucleic acid testing: results of screening more than 30 million blood donations for human 
immunodeficiency virus-1, hepatitis $\mathrm{C}$ virus, and hepatitis $\mathrm{B}$ virus. Transfusion 2008;48:1558-66.

[33] Sun Z, Ming L, Zhu X, Lu J. Prevention and control of hepatitis B in China. J Med Virol 2002;67:447-50.

[34] Zhou YH, Wu C, Zhuang H. Vaccination against hepatitis B: the Chinese experience.Chin Med J (Engl) 2009;122:98-102.

[35] Wang J, Lu FM, Zhuang H. The analysis on the epidemic trend of viral hepatitis in China during recent 10 years (2002-2011). Zhonghua Gan Zang Bing Za Zhi 2013;21(8):561-4.

[36] Ma L, Alla NR, Li X, Mynbaev OA, Shi Z. Mother-to-child transmission of HBV: review of current clinical management and prevention strategies. Rev Med Virol $2014 ; 24: 396-406$.

[37] Ni YH, Chang MH, Wu JF, Hsu HY, Chen HL, Chen DS. Minimization of hepatitis $\mathrm{B}$ infection by a 25-year universal vaccination program. J Hepatol.2012;57:730-5.

[38] Zheng X, Ye X, Du P, Zeng J, Zhu W, Yang B, et al. High prevalence of anti-hepatitis B core antigen in hepatitis B virus-vaccinated Chinese blood donors suggests insufficient protection but little threat to the blood supply. Transfusion. 2014;55:890-7.

[39]Qin Y , Liao P. Hepatitis B virus vaccine breakthrough infection: surveillance of S gene mutants of HBV. Acta Virologica,2018;62(02):115-121.

[40] Candotti D, Allain JP. Transfusion-transmitted hepatitis B virus infection.J Hepatol. 2009;51:798-809

[41] Gerlich WH, Wagner FF, Chudy M, et al. HBsAg non reactive HBV infection in blood donors: Transmission and pathogenicity. Journal of Med Virol 2007; 79: S32-S36.

[42] Delwart E, Slikas E, Stramer SL, Kamel H, Kessler D, Krysztof D, Tobler LH, Carrick DM, Steele W, Todd D, Wright DJ, Kleinman SH, Busch MP: Genetic diversity of recently acquired and prevalent HIV, hepatitis B virus, and hepatitis $\mathrm{C}$ virus infections in US blood donors. J Infect Dis 2012;205:875-885. 


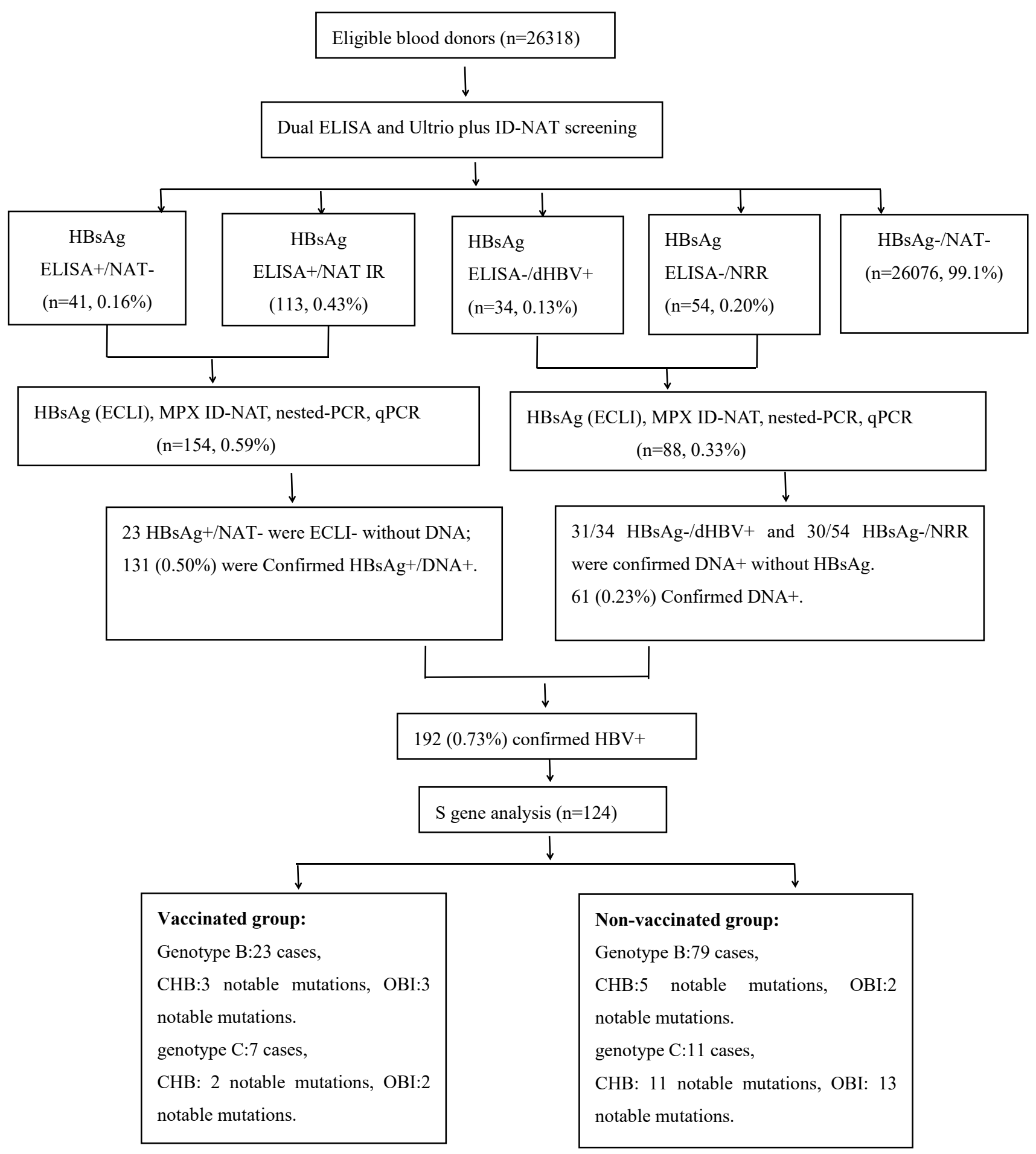

Figure 1. Flowchart for confirmatory testing algorithm of HBsAg ELISA+ and /or NAT IR samples 
Table 1. Demographic Characteristics of Vaccinated and Non-vaccinated Donors from Jan. 2016 to Jul. 2016

\begin{tabular}{|c|c|c|c|c|}
\hline & $\begin{array}{c}\text { Over all } \\
\text { Population (\%) }\end{array}$ & $\begin{array}{c}\text { vaccinated group } \\
(\%)\end{array}$ & $\begin{array}{c}\text { non-vaccinated group } \\
(\%)\end{array}$ & $\mathrm{P}$ \\
\hline \multicolumn{5}{|l|}{ Donors Status } \\
\hline First-time & $14738(56.0)$ & $4810(74.9)$ & 9929 (49.9) & \multirow[t]{2}{*}{0.00} \\
\hline Repeat & $11580(44.0)$ & $1611(25.1)$ & $9968(50.1)$ & \\
\hline \multicolumn{5}{|l|}{ Gender } \\
\hline Male & $16975(64.5)$ & $3501(54.5)$ & $13475(67.7)$ & \multirow[t]{2}{*}{0.00} \\
\hline Female & $9343(35.5)$ & $2920(45.5)$ & $6422(32.3)$ & \\
\hline \multicolumn{5}{|l|}{ Occuption } \\
\hline Farmers & $482(18.2)$ & $28(0.4)$ & $454(2.3)$ & \multirow{9}{*}{0.00} \\
\hline Workers & $4173(15.8)$ & $472(7.3)$ & 3701 (18.6) & \\
\hline Students & $1778(6.7)$ & $1653(25.7)$ & $125(0.6)$ & \\
\hline Soldiers & $150(0.5)$ & $76(1.2)$ & $74(0.4)$ & \\
\hline Teachers & $287(1.1)$ & $79(1.2)$ & $208(1.0)$ & \\
\hline Civil servants & $255(1.0)$ & $26(0.4)$ & $229(1.1)$ & \\
\hline Doctors & $369(1.3)$ & $101(1.6)$ & $268(1.3)$ & \\
\hline Staff & $9920(37.7)$ & $1797(28.0)$ & $8123(40.8)$ & \\
\hline Others & $8904(33.8)$ & $2189(34.1)$ & $6715(33.7)$ & \\
\hline \multicolumn{5}{|l|}{ Education } \\
\hline Below High School & $5405(20.5)$ & $1290(20.1)$ & $4115(20.7)$ & \multirow{6}{*}{0.00} \\
\hline High School and Assodate Degree & $15565(59.1)$ & $3970(61.8)$ & $11595(58.2)$ & \\
\hline Bachelor's Degree & $4852(18.4)$ & $1131(17.6)$ & 3721 (18.7) & \\
\hline Master's Degree & $338(1.3)$ & $22(0.3)$ & $316(1.5)$ & \\
\hline Others & $158(0.6)$ & $8(0.1)$ & $150(0.8)$ & \\
\hline Total & $26318(100)$ & $6421(24.4)$ & $19897(75.6)$ & \\
\hline
\end{tabular}


Table 2. Classification of 192 infected blood donors between vaccinated and non-vaccinated groups

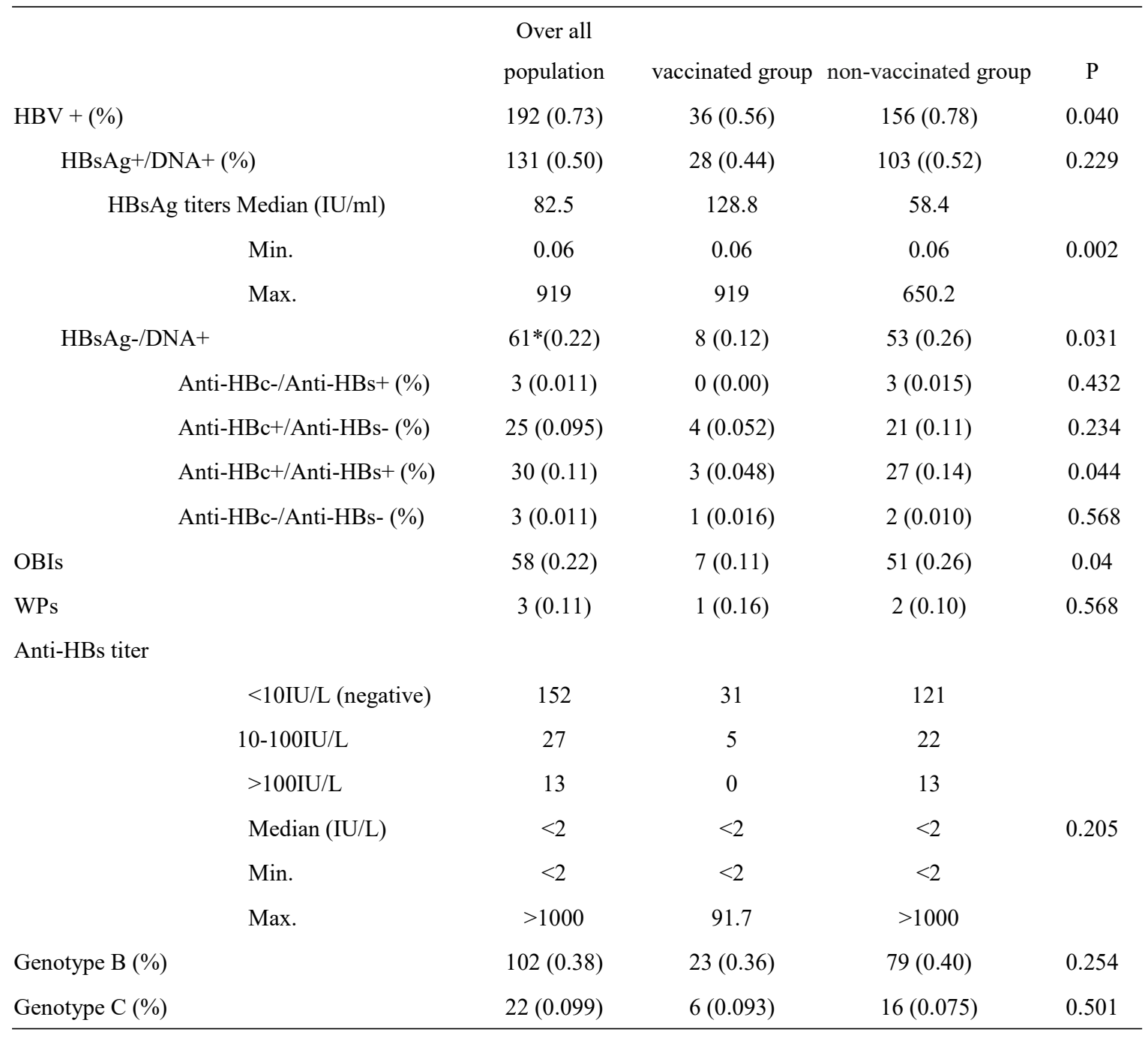

* 2 WP and 57 OBI.HBsAg <0.05IU/ml:Negative. Anti-HBs <10IU/L:Negative 
Table 3. Notable mutations in envelope proteins of HBV DNA+ donations

\begin{tabular}{|c|c|c|c|c|c|c|c|c|}
\hline $\begin{array}{l}\text { Gen } \\
\text { otyp } \\
\text { e }\end{array}$ & $\begin{array}{l}\text { Infect } \\
\text { ions }\end{array}$ & Group & Mutation & Frequency (\%) & $\begin{array}{l}\text { Vaccine } \\
\text { escape } \\
\text { mutant }\end{array}$ & $\begin{array}{l}\text { Affect } \\
\text { Serological } \\
\text { diagnosis }\end{array}$ & $\begin{array}{l}\text { Failure in } \\
\text { HBIg } \\
\text { Therapy }\end{array}$ & $\begin{array}{l}\text { Refere } \\
\text { nces }\end{array}$ \\
\hline \multirow{22}{*}{ B } & \multirow{13}{*}{$\mathrm{CHB}$} & \multirow{8}{*}{$\begin{array}{l}\text { Non-v } \\
\text { accina } \\
\text { ted }\end{array}$} & $\mathrm{N} 40 \mathrm{~S} / \mathrm{F}$ & $(25+1) / 65(40)$ & This study & This study & This study & \\
\hline & & & $\mathrm{I} 68 \mathrm{~T} / \mathrm{M}$ & $(2+2) / 65(6.2)$ & This study & This study & This study & \\
\hline & & & Q101R/H/ & $(2+1+1) / 65(6.2)$ & This study & Yes (Q101K) & This study & [13] \\
\hline & & & $\mathrm{K}$ & & & & & \\
\hline & & & $\mathrm{M} 133 \mathrm{~L} / \mathrm{T} /$ & $(11+5+2) / 65(27.7$ & Yes & Yes & Yes & {$[14,15]$} \\
\hline & & & $\mathrm{S}$ & ) & (M133L,M & (M133L),M1 & (M133L) & \\
\hline & & & & & $133 \mathrm{~T})$ & $33 \mathrm{~T})$ & & \\
\hline & & & $\mathrm{F} 134 \mathrm{I} / \mathrm{L} / \mathrm{S}$ & $(3+1+1) / 65(7.8)$ & This study & Yes (F134L) & This study & {$[15]$} \\
\hline & & \multirow{5}{*}{$\begin{array}{l}\text { vaccin } \\
\text { ated }\end{array}$} & $\mathrm{G} 44 \mathrm{D} / \mathrm{E}$ & $(8+1) / 21(38.1)$ & This study & This study & This study & \\
\hline & & & M133L & $11 / 21(52.4)$ & Yes & Yes & Yes & {$[14,15]$} \\
\hline & & & & & (M133L,M & (M133L),M1 & (M133L) & \\
\hline & & & & & $133 \mathrm{~T})$ & $33 \mathrm{~T})$ & & \\
\hline & & & E164G & $3 / 21(14.3)$ & Yes(E164G) & Yes(E164G) & This study & {$[16]$} \\
\hline & \multirow{9}{*}{ OBI } & \multirow{4}{*}{$\begin{array}{l}\text { Non-v } \\
\text { accina } \\
\text { ted }\end{array}$} & $\mathrm{G} 44 \mathrm{D} / \mathrm{E}$ & $(5+1) / 14(42.9)$ & This study & This study & This study & \multirow{4}{*}[14,15]{} \\
\hline & & & M133L & $9 / 14(64.3)$ & Yes & Yes & Yes & \\
\hline & & & & & (M133L,M & (M133L),M1 & (M133L) & \\
\hline & & & & & $133 \mathrm{~T})$ & $33 \mathrm{~T})$ & & \\
\hline & & vaccin & $\mathrm{K} 24 \mathrm{R}$ & $2 / 2(100)$ & This study & This study & This study & \\
\hline & & ated & G44D & $2 / 2(100)$ & This study & This study & This study & \\
\hline & & & M133L & $2 / 2(100)$ & Yes & Yes & Yes & {$[14,15]$} \\
\hline & & & & & (M133L,M & (M133L),M1 & (M133L) & \\
\hline & & & & & 133T) & $33 \mathrm{~T})$ & & \\
\hline \multirow{16}{*}{$\mathrm{C}$} & \multirow{14}{*}{$\mathrm{CHB}$} & \multirow{11}{*}{$\begin{array}{l}\text { Non-v } \\
\text { accina } \\
\text { ted }\end{array}$} & Q30K & $3 / 5(60)$ & This study & This study & This study & \\
\hline & & & S34L & $3 / 5(60)$ & This study & Yes (S34L) & This study & [17] \\
\hline & & & N40S & $4 / 5(80)$ & This study & This study & This study & \\
\hline & & & $\mathrm{A} 45 \mathrm{~T}$ & $3 / 5(60)$ & Yes (S45T) & This study & This study & {$[18]$} \\
\hline & & & $\mathrm{T} 47 \mathrm{~V}$ & $3 / 5(60)$ & $*$ & This study & This study & \\
\hline & & & $\mathrm{P} 49 \mathrm{H}$ & $3 / 5(60)$ & This study & This study & This study & \\
\hline & & & $\mathrm{S} 55 \mathrm{~F}$ & $3 / 5(60)$ & This study & This study & This study & \\
\hline & & & $\mathrm{I} 68 \mathrm{~T}$ & $3 / 5(60)$ & This study & This study & This study & \\
\hline & & & $\mathrm{P} 79 \mathrm{H}$ & $3 / 5(60)$ & This study & This study & This study & \\
\hline & & & L175S & $3 / 5(60)$ & $*$ & Yes (L175S) & This study & [19] \\
\hline & & & V177A & $3 / 5(60)$ & This study & Yes (V177A) & This study & [19] \\
\hline & & \multirow{3}{*}{$\begin{array}{l}\text { vaccin } \\
\text { ated }\end{array}$} & $\mathrm{T} 118 \mathrm{~K}$ & $1 / 3(33.3)$ & Yes & Yes (T118R) & Yes & {$[13]$} \\
\hline & & & & & (T118R) & & (T118R) & \\
\hline & & & L175S & $1 / 3(33.3)$ & $*$ & Yes (L175S) & This study & [19] \\
\hline & \multirow{2}{*}{ OBI } & Non-v & Q30K & $4 / 11(36.4)$ & This study & This study & This study & \\
\hline & & accina & N40S & $5 / 11(45.5)$ & This study & This study & This study & \\
\hline
\end{tabular}




\begin{tabular}{|c|c|c|c|c|c|c|}
\hline \multirow[t]{12}{*}{ ted } & $\mathrm{A} 45 \mathrm{~T}$ & $5 / 11(45.5)$ & This study & This study & This study & \\
\hline & $\mathrm{T} 47 \mathrm{~V} / \mathrm{K}$ & $(5+1) / 11(54.5)$ & $*$ & This study & This study & \\
\hline & $\mathrm{P} 49 \mathrm{H} / \mathrm{L}$ & $(4+1) / 11(45.5)$ & This study & This study & This study & \\
\hline & S55F & 4/11(36.4) & This study & This study & This study & \\
\hline & $\mathrm{R} 59 \mathrm{H}$ & 4/11(36.4) & This study & This study & This study & \\
\hline & $\mathrm{T} 113 \mathrm{P} / \mathrm{S} / \mathrm{N}$ & $(1+1+1) / 11(27.3)$ & This study & This study & This study & \\
\hline & $\mathrm{T} 118 \mathrm{~K} / \mathrm{R}$ & $(2+1) / 11(27.3)$ & Yes & Yes & Yes & [13] \\
\hline & & & (T118R) & (T118R) & (T118R) & \\
\hline & $\mathrm{S} 143 \mathrm{~T} / \mathrm{L}$ & $(2+1) / 11(27.3)$ & This study & Yes (S143L) & & [18] \\
\hline & $\mathrm{R} 160 \mathrm{~K} / \mathrm{N}$ & $(7+1) / 11(72.8)$ & This study & This study & This study & \\
\hline & L175S & 4/11(36.4) & $*$ & Yes (L175S) & This study & [19] \\
\hline & V177A & $4 / 11(36.4)$ & This study & Yes (V177A) & This study & [19] \\
\hline vaccin & L53S & $2 / 3(66.7)$ & This study & This study & This study & \\
\hline ated & $\mathrm{I} 126 \mathrm{~S} / \mathrm{T}$ & $(1+1) / 3(66.7)$ & Yes (I126S) & Yes (I126S) & This study & [15] \\
\hline
\end{tabular}

This study: not determined in this study.* be under positive selection in genotype B and C HBV vaccine escape strains [20]; N40S substitutions found interfere with virion production [21].HBig:hepatitis B immunoglobulin. 


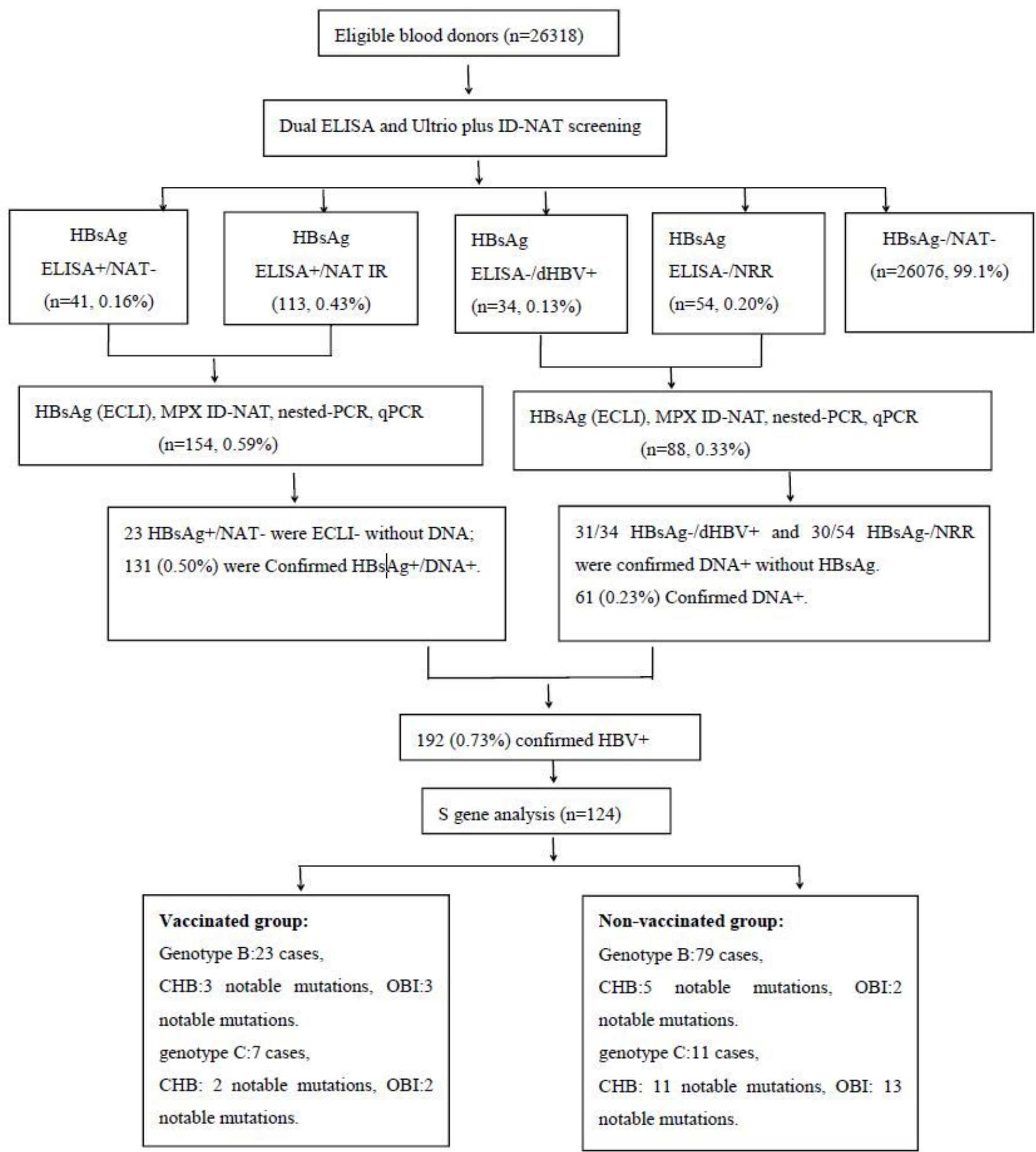

\section{Figure 1}

Flowchart for confirmatory testing algorithm of HBsAg ELISA+ and /or NAT IR samples 